both heard and empowered and felt all the information they offered was precious.

Discussion Patients found it a powerful experience and felt they made a contribution for the future. Professionals gained emotional and practical insights which inspired motivation for change in service delivery. The process tapped into strong motivations for mutual understanding. It is an effective element in developing person-centred COPD services and is transferable to other LTCs.

Supported by grant from the Health Foundation

\section{P94 PATIENT AGENDA SETTING AND CLINIC EFFICIENCY IN OUTPATIENTS: AN INDIVIDUAL RANDOMISED CONTROLLED TRIAL}

A Everden, F Early, K Homan, J Fuld. Cambridge University Hospitals NHS Foundation Trust, Cambridge, UK

\subsection{6/thoraxjnl-2014-206260.235}

Introduction Most patients have issues to raise in a consultation but may not actually raise them, adversely affecting the consultation outcome. Evidence suggests that methods to help patients consider their information needs before a consultation can increase satisfaction without increasing consultation length but there is a need to assess a wider range of outcome measures and to measure consultation length accurately.

We studied the impact of a paper agenda form to prompt question asking in a respiratory outpatient clinic. The primary objective was to identify whether this increased agreement that "My doctor discussed the issues that were important to me". Secondary endpoints included consultation length and post-consultation confidence to self-manage (0-10 scale).

Method Patients were randomised to receive the agenda form or usual care by blocked randomization (block size 6), stratified by consultant. Patients receiving the form had a written brief inviting them to complete it in the waiting room.

PROMs were collected post-consultation. Consultations were timed by an observer outside the room. As planned in the protocol, categorical data were analysed using Fisher's exact test and continuous data were analysed using a t-test. Exploratory

\begin{tabular}{|c|c|c|c|c|}
\hline & & $\begin{array}{l}\text { Agenda } \\
\text { form } N=83\end{array}$ & $\begin{array}{l}\text { Usual care } \\
\mathbf{N}=\mathbf{8 0}\end{array}$ & P-value \\
\hline My doctor discussed the issues & SD* $^{*}$ & $1(1.2 \%)$ & & \\
\hline that were important to me & $\begin{array}{l}\text { A } \\
\text { SA }\end{array}$ & $\begin{array}{l}17(20.5 \%) \\
63(75.9 \%)\end{array}$ & $\begin{array}{l}21(26.3 \%) \\
56(70.0 \%)\end{array}$ & 0.4567 \\
\hline $\begin{array}{l}\text { I raised with my doctor the issues } \\
\text { that were important to me }\end{array}$ & $\begin{array}{l}\text { SD } \\
\text { A } \\
\text { SA }\end{array}$ & $\begin{array}{l}1(1.2 \%) \\
21(25.3 \%) \\
57(68.7 \%)\end{array}$ & $\begin{array}{l}18(22.5 \%) \\
59(73.8 \%)\end{array}$ & 0.6464 \\
\hline $\begin{array}{l}\text { I got the outcome I wanted from } \\
\text { my consultation }\end{array}$ & $\begin{array}{l}\text { SD } \\
\text { D } \\
\text { A } \\
\text { SA }\end{array}$ & $\begin{array}{l}1(1.2 \%) \\
2(2.4 \%) \\
18(21.7 \%) \\
58(69.9 \%)\end{array}$ & $\begin{array}{l}2(2.5 \%) \\
24(30.0 \%) \\
50(62.5 \%)\end{array}$ & 0.4591 \\
\hline $\begin{array}{l}\text { How confident do you feel that you can } \\
\text { take steps to manage your condition } \\
\text { as a result of today's visit? (0-10) }\end{array}$ & $\begin{array}{l}n \\
\text { Mean (SD) } \\
\text { Median } \\
\text { Min, Max }\end{array}$ & $\begin{array}{l}79 \\
8.7(1.92) \\
10 \\
3,10\end{array}$ & $\begin{array}{l}73 \\
8.7(1.34) \\
9 \\
5,10\end{array}$ & 0.795 \\
\hline Consultation duration (mins) & $\begin{array}{l}\mathbf{n} \\
\text { Mean (SD) } \\
\text { Median } \\
\text { Min, Max }\end{array}$ & $\begin{array}{l}83 \\
15.2(7.69) \\
13 \\
3,40\end{array}$ & $\begin{array}{l}78 \\
15.3(7.98) \\
14.8 \\
2,44\end{array}$ & 0.908 \\
\hline $\begin{array}{l}\text { *SD (Strongly Disagree) } \\
\text { D (Disagree) } \\
\text { A (Agree) } \\
\text { SA (Strongly Agree) }\end{array}$ & & & & \\
\hline
\end{tabular}

analyses to assess the effects of a number of factors used mixed model ANOVA.

Results Groups were well matched at baseline for age, gender and respiratory diagnosis. There was no significant effect of agenda form use on the primary or secondary endpoints (Table 1). Exploratory analyses identified that in new patients (but not in follow-up patients) the form was associated with shorter consultation length (LS mean $=15.2$ mins) than usual care (LS mean $=21.3$ mins) $(\mathrm{p}=$ $0.017)$ and with lower confidence to self-manage (LS mean=6.6) than usual care (LS mean=9.2) $(\mathrm{p}=0.001)$.

Conclusion There was no overall benefit from the form and a risk of detrimental impact on patient experience for some patients. This resonates with reports from other more complex self-management interventions that have found unexpected detrimental effects in some patients. There is a need for greater understanding of what works for whom with regard to self-management support. It cannot be assumed that the impact will be universally beneficial at best or neutral at worst.

\section{REFERENCE}

1 Trial reference: REC reference: 13/WA/0171

\section{P95 NON CF BRONCHIECTASIS}

CJ Baggott, E Harris, J Suntharalingam, AS Malin. Royal United Hospitals Bath, Bath, UK

\subsection{6/thoraxjnl-2014-206260.236}

Background Bronchiectasis is said to affect 100/100 000, however the true prevalence is probably significantly higher. Our previous BTS bronchiectasis audit identified that a significant service improvement was required. This led to the introduction of a home intravenous antibiotic pilot, a bronchiectasis working group, and enhanced teaching and information sharing with primary care. Despite this, these patients remain poorly served both in the community and hospital.

From 2009-13 there were 330 bronchiectasis admissions to our hospital. A significant proportion of these could have been managed in the community, substantially reducing the cost to the NHS. Aims We are developing an integrated bronchiectasis service between hospital and community. The vision has been to create a primary and secondary care interface, utilising the usual multidisciplinary team plus psychology and dietetic support, a 'hospital without walls' model and an online, multi-faceted communication tool.

\section{Integrated bronchiectasis care pathway}

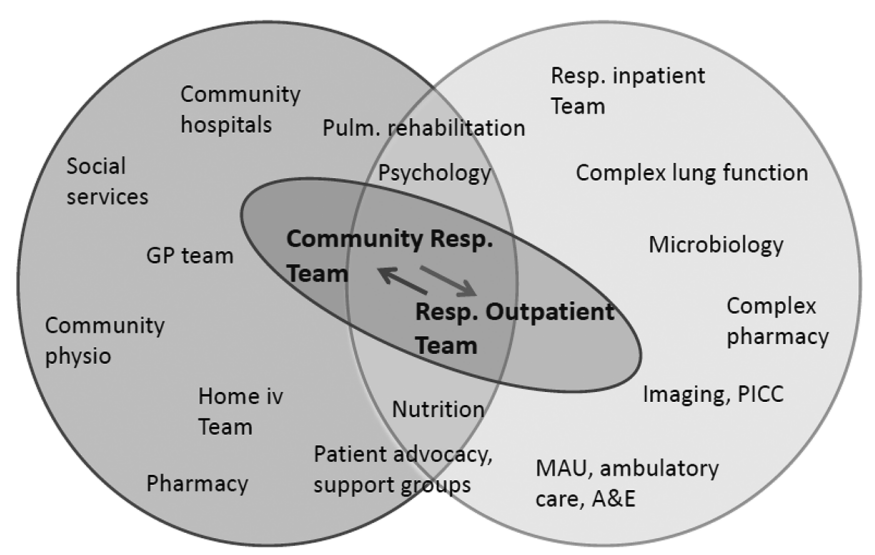

Abstract P95 Figure 1 